\title{
Suppression of Lipopolysaccharide-Stimulated Neuroinflammatory Mediators by Chenopodiacea Mangrove, Suaedea maritima (L) Dumort, in BV-2 Microglial Cells
}

\author{
Hyun Kang \\ Department of Medical Laboratory Science, College of Health Science, Dankook University, Cheonan-si, Chungnam, 330-714, \\ Republic of Korea
}

*For correspondence: Email: hyunbio@gmail.com, hkang@dankook.ac.kr; Tel: 82-41-550-1452; Fax: 82-41-559-7934

Received: 26 August 2014

Revised accepted: 11 September 2014

\begin{abstract}
Purpose: To investigate the in-vitro antioxidant and anti-neuroinflammatory effects of Suaeda maritime (L) Dumort ethyl acetate (SM-EA) extract in lipopolysaccharide (LPS)-stimulated BV-2 microglial cells. Methods: LPS-stimulated BV- microglia were used to study the expression and production of inflammatory mediators, viz, nitric oxide (NO), inducible NO synthase (iNOS, interleukin (IL)-6) and tumor necrosis alpha (TNF- $\alpha$ ). Antioxidant activity was measured using 1, 1-diphenyl-2-picryl-hydrazyl (DPPH) assay. Cell viability was estimated by 3-(4, 5-dimethylthiazol-2-yl)-2, 5- diphenyl-tetrazolium bromide (MTT) assay.

Results: SM-EA extract significantly suppressed LPS-induced production of NO ( $p<0.001$ at 80 and $100 \mu \mathrm{g} / \mathrm{ml}$ ) and expression of iNOS in BV-2 cells. SM-EA also suppressed LPS-induced increase in IL-6 and TNF- $\alpha$ levels ( $p<0.001 \mathrm{at} 100 \mu \mathrm{g} / \mathrm{ml})$ in BV-cells. Further, DPPH-generated free radicals were inhibited by SM-EA extract in a concentration-dependent manner $(p<0.01$ at $0.1 \mathrm{mg} / \mathrm{ml}$ and $p<0.001$ at $1 \mathrm{mg} / \mathrm{ml}$ ) with half maximal inhibitory concentration (IC50) of $0.42 \mathrm{mg} / \mathrm{ml}$.

Conclusion: The findings imply that SM-EA extract can be developed as a potential therapeutic agent in regulating microglia-mediated neuroinflammatory responses observed in several neurodegenerative diseases.
\end{abstract}

Keywords: Suaedea maritime, Chenopodiaceae, Anti-oxidant, Anti-inflammatory, Microglial cells, Inducible nitric oxide synthase, Interleukin-6

Tropical Journal of Pharmaceutical Research is indexed by Science Citation Index (SciSearch), Scopus, International Pharmaceutical Abstract, Chemical Abstracts, Embase, Index Copernicus, EBSCO, African Index Medicus, JournalSeek, Journal Citation Reports/Science Edition, Directory of Open Access Journals (DOAJ), African Journal Online, Bioline International, Open-J-Gate and Pharmacy Abstracts

\section{INTRODUCTION}

Suaeda maritima (L) Dumort, from the family Chenopodiaceae, is an annual salt-tolerant plant species seen abundantly on muddy seashores in Korea, Europe, Japan and Iran. The leaves are used as vegetable to reduce saltiness and also pickled in vinegar for consumption [1 Tanaka]. Traditionally, S. maritima has been used as herbal remedy for treating hepatitis and reported to possess anti-viral activities [2]. Pharmacologically, S. maritima was reported to possess antimicrobial, antioxidant and hepatoprotective activities due to the presence of triterpinoids and sterols [2,3]. However, studies on its beneficial effects on microglia- mediated neuroinflammatory diseases have not been reported. 
Neuroinflammation mediated by microglial activation appears to play an essential role in the pathogenesis of neurodegenerative diseases [4]. It was well documented that activated microglia releases proinflammatory mediators and free radicals which may participate progressive neurodegeneration. Therefore early attenuation of activated microglia and the neuroinflammatory processes can attenuate the severity of neurodegeneration [5].

Mounting evidence indicated that microbial endotoxins like LPS can directly activate microglia triggering the production of proinflammatory mediators, such as nitric oxide (NO), inducible NO synthase (iNOS), interleukins (IL) and tumor necrosis factor (TNF)- $\alpha$ [6]. Therefore, LPS-induced stimulation to microglia might be used as an important tool to evaluate the changes caused by activated microglia in vitro. Studies have shown that anti-oxidant and anti-inflammatory agents may inhibit microglial activation and thus protect neuronal cell death seen in various neurodegenerative disorders $[7,8]$. In this study we evaluated the in vitro antioxidant potential and anti-neuroinflammatory properties of $S$. maritima ethyl accrete (SM-EA) extract in LPS-stimulated BV-2 microglial cells.

\section{EXPERIMENTAL}

\section{Preparation of S. maritima extract}

S. maritima whole plant was collected from the western coast region in South Korea. The plant was authenticated by a taxonomist, Dr Kim Jong Bo at Konkuk University, South Korea and a voucher specimen (SM-KU2013) was stored in our department herbarium for future reference. To obtain the S. maritima extract, the dried plant material was ground in a mixer and defatted with three volumes of ethanol, three times. The residue was extracted with absolute ethanol at $1: 10$ ratio $(\mathrm{w} / \mathrm{v})$ for $2 \mathrm{~h}$ in heating mantle at $70-$ $80{ }^{\circ} \mathrm{C}$. The supernatant was filtered and concentrated in vacuum evaporator system at 50 ${ }^{\circ} \mathrm{C}$. For further fractionation, alcoholic extract (500 mg) was partitioned into hexane, chloroform and ethyl acetate (EA) fractions to furnish 110.5 $\mathrm{mg}, 16.6 \mathrm{mg}$ and $174.6 \mathrm{mg}$, respectively. The active EA fraction of $S$. maritima designated as SM-EA was re-dissolved in distilled water to evaluate for its anti-neuroinflammatory and antioxidant activities.

\section{DPPH radical scavenging activity}

The anti-oxidant activity of the SM-EA EXTRACT was determined using the stable radical 2, 2diphenyl-1-picrylhydrazyl (DPPH, Sigma-Aldrich,
St Louis, MO, USA). The radical scavenging capacity was evaluated by employing a reaction mixture constituted by aliquots of the SM-EA extract and a DPPH methanolic solution as described previously [9]. Briefly, a sample solution of $60 \mu \mathrm{l}$ of each SM-EA extract, was added to $60 \mu \mathrm{l}$ of DPPH $(60 \mu \mathrm{M})$ in methanol. After mixing vigorously for $10 \mathrm{~s}$, the mixture was then transferred into a $100 \mu \mathrm{l}$ Teflon capillary tube and the scavenging activity of each sample on DPPH radical was measured using a JES-FA ESR spectrometer (Jeol Ltd., Tokyo, Japan). A spin adduct was measured on an ESR spectrometer exactly after $2 \mathrm{~min}$. Experimental conditions were as follows: central field, 3,475 G; modulation frequency, $100 \mathrm{kHz}$; modulation amplitude, $2 \mathrm{G}$; microwave power, $5 \mathrm{~mW}$; gain, $6.3 \times 10^{5}$, and temperature, $298^{\circ} \mathrm{K}$.

\section{Cell cultures and viabilities}

BV-2 microglia cells were cultured at $37^{\circ} \mathrm{C}$ in 5 $\% \mathrm{CO}_{2}$ in DMEM (Invitrogen, Carlsbad, CA, USA) supplemented with $5 \%$ FBS (Hyclone, Logan, UT, USA) and antibiotics (Invitrogen). In all experiments, cells were pre-treated with the indicated concentrations of SM-EA extract for $1 \mathrm{~h}$ before the addition of LPS $(1 \mu \mathrm{g} / \mathrm{ml}$, SigmaAldrich, St. Louis, MO, USA) in serum free DMEM. An equal volume of sterile water was added to all control treatments. Cell viability was determined by 3-(4, 5-dimethylthiazol-2-yl)-2,5diphenyltetrazolium bromide (MTT) assay as described previously [10]. Cells were incubated with various concentrations of SM-EA extract for $24 \mathrm{~h}$ followed by MTT for $4 \mathrm{~h}$, and then $100 \mu \mathrm{l}$ of isopropanol (in $0.04 \mathrm{~N}$-hydrochloric acid) was added to dissolve the formazan crystals. The absorbance was read at $570 \mathrm{~nm}$ using the Anthos 2010 spectrophotometer (Salzburg, Austria). Cell viability was calculated as relative absorbance compared to control.

\section{Nitric oxide assay}

The amount of stable nitrite, the end product of NO generation, by activated microglia was determined by a colorimetric assay as previously described [10]. Briefly, $50 \mu \mathrm{l}$ of culture supernatant was mixed with an equal volume of Griess reagent and incubated at room temperature for $10 \mathrm{~min}$. The absorbance at 540 $\mathrm{nm}$ was read using a PowerWavex Microplate Scanning spectrophotometer (Bio-Tek Instrument, Winooski, VT, USA). Nitrite concentration was determined by extrapolation from a sodium nitrite standard curve. 


\section{Western blot analysis}

Cells were washed in cold PBS three times and lysed in a buffer containing $50 \mathrm{mM}$ Tris- $\mathrm{HCl}, \mathrm{pH}$ $7.4, \quad 1 \%$ (v/v) NP-40, $0.25 \%$ sodium deoxycholate, $150 \mathrm{mM} \mathrm{NaCl}, 1 \mathrm{mM}$ EDTA, 25 $\mathrm{mM} \mathrm{NaF}, 2 \mathrm{mM} \mathrm{Na} \mathrm{VO}_{4}$ and protease inhibitor cocktail (Complete MiniTM, Roche, Mannheim, Germany) at $4{ }^{\circ} \mathrm{C}$. The lysate was clarified by centrifugation at $10,000 \times \mathrm{g}$ for $20 \mathrm{~min}$ at $4{ }^{\circ} \mathrm{C}$ to remove insoluble components. Cell lysates were normalized for protein content using BCA reagent (Pierce, Rockford, IL, USA). Equal amounts of protein were loaded onto $10 \%$ PAGE gels and separated by standard SDS-PAGE procedure. Proteins were transferred to an NC membrane (S\&S, Dassel, Germany) and blocked with $5 \%$ non-fat dry milk in TBS. To detect protein expression, the blots were probed with the specific antibodies followed by the secondary antibodies coupled to horseradish peroxidase (Bio-Rad, Herculus, CA, USA) with $\beta$-actin as internal control. The immunoreactive proteins on the membrane were detected by chemiluminescence using the West-Save substrate (Lab-Frontier, Seoul, Korea) on X-ray film. The antibodies against iNOS and $\beta$-actin were purchased from Cell Signaling Technology INC. (Beverly, MA, USA).

\section{IL-6 assay}

BV-2 microglia cells $\left(1 \times 10^{5}\right.$ cells/well) were cultured on 96 well plates and treated with SMEA extract at indicated dosages with or without LPS $(1 \mu \mathrm{g} / \mathrm{ml})$. At $4 \mathrm{~h}$ of post LPS treatment, the cells were collected and the supernatants were subjected to estimate IL-6 contents using a murine IL-6 ELISA kit from BD Biosciences (San Jose, CA, USA) according to the manufacturer's instruction.

\section{TNF- $\alpha$ assay}

BV-2 microglia cells $\left(1 \times 10^{5}\right.$ cells/well) were cultured on 96 well plates and treated with the SM-EA extract at indicated concentrations for $1 \mathrm{~h}$ and stimulated with LPS $(1 \mu \mathrm{g} / \mathrm{ml})$. At $4 \mathrm{~h}$ post LPS treatment, the cells were collected and the supernatants were evaluated for TNF- $\alpha$ level using a murine TNF- $\alpha$ ELISA kit from BD Biosciences (San Jose, CA, USA) according to the manufacturer's instructions.

\section{Statistical analysis}

All data are represented as the mean \pm S.E.M of at least three independent experiments. Statistical analyses were performed using SAS statistical software (SAS Institute, Cray, NC,
USA) using one-way analysis of variance, followed by Dunnett's multiple range tests. $P<0.05$ was considered statistically significant.

\section{RESULTS}

\section{Effect of SM-EA extract on DPPH radical scavenging activity}

DPPH is a stable free radical, and accepts an electron or hydrogen radical to become a stable diamagnetic molecule which has been used to evaluate free radical scavenging activity of natural anti-oxidants. The capacity of SM-EA extract to scavenge DPPH was measured by ESR spectrometry. As shown in Fig 1A, SM-EA extract exhibited significant $\mathrm{DPPH}$ radical scavenging activity in a dose-dependent manner showing a maximum effect at $1 \mathrm{mg} / \mathrm{ml}$ of concentration $(p<0.001)$. The concentration needed for $50 \%$ inhibition of DPPH radicals was found to be approximately at $0.42 \mathrm{mg} / \mathrm{ml}$. The ESR spectroscopy data at $0.01,0.1$ and $1 \mathrm{mg} / \mathrm{ml}$ was represented in Fig $1 \mathrm{~B}$.

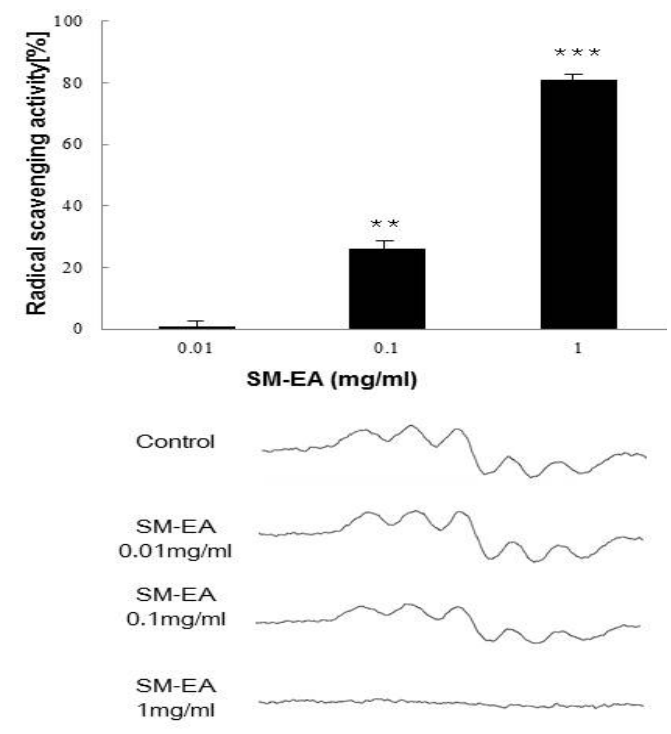

Fig 1: Effect of SM-EA extract on DPPH radical scavenging activity. The capacity to scavenge DPPH free radical by different concentrations of SM-EA extract $(A)$ and ESR spectra (B) was measured. BV-2 cells were treated with or without SM-EA extract at the various concentrations $(0.01$, 0.1 and $1 \mathrm{mg} / \mathrm{ml}$ ). The scavenging activity of each sample on DPPH radical was measured using a JES-FA ESR spectrometer. A spin adduct was measured on an ESR spectrometer exactly 2 min later. Data are presented as the mean \pm S.E.M. $(n=3)$ for three independent experiments. ${ }^{* *} p$ $<0.01$ and ${ }^{* *} p<0.001$, when compared with control group by one-way analysis of variance, followed by Dunnett's multiple range tests. SM-EA extract $=$ Suaeda maritima ethyl acetate extract 


\section{Effect of SM-EA extract on LPS-induced NO production}

BV-2 microglia were treated with various concentrations of SM-EA EXTRACT (10, 20, 40, 80 and $100 \mu \mathrm{g} / \mathrm{ml}$ ) for $30 \mathrm{~min}$ prior to LPS (1 $\mu \mathrm{g} / \mathrm{ml}$ ) stimulation for $4 \mathrm{~h}$. As shown in Fig. 2, NO production by LPS-activated cells was found to be significantly inhibited by SM-EA extract in a concentration-dependent manner (Fig. 2). The maximum effect was shown at 80 and $100 \mu \mathrm{g} / \mathrm{ml}$ $(p<0.001)$. Further, SM-EA extract treatment did not exhibit any significant cytotoxicity in BV-2 microglial cells treated for $24 \mathrm{~h}$ at concentrations up to $100 \mu \mathrm{g} / \mathrm{ml}$, and in all cases the viability was found above $93 \%$ by MTT assay (Fig 3 ).

\section{Effect of SM-EA extract on LPS-induced expressional levels of iNOS}

To know the effect of SM-EA extract on iNOS levels, BV-2 cells were stimulated with LPS (1 $\mu \mathrm{g} / \mathrm{ml}$ ) in the presence or absence of SM-EA extract (50 and $100 \mu \mathrm{g} / \mathrm{ml}$ ). LPS strongly induced BV-2 cells showing an increased expression of iNOS. However, treatment with SM-EA extract exhibited a broad spectrum of inhibitory effect on the expression of iNOS induced by LPS in BV-2 cells (Fig 4).

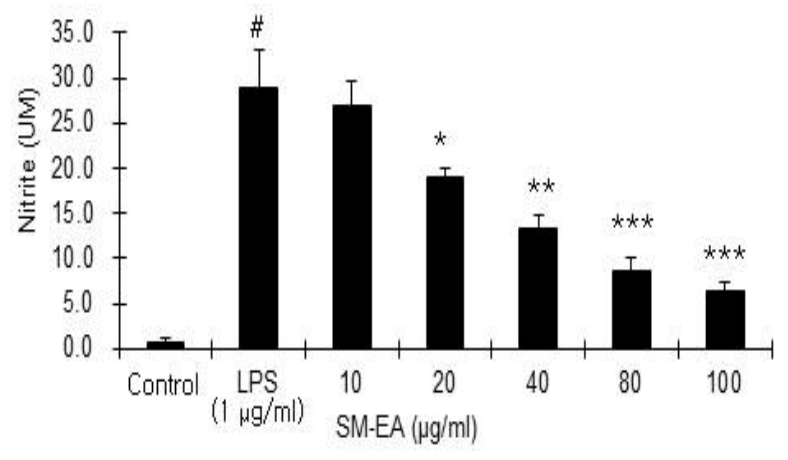

Fig 2: Effect of SM-EA extract on NO Production in LPS-stimulated BV-2 microglial cells. BV-2 cells were treated with SM-EA extract at various concentrations $(10,20,40,80$, and $100 \mu \mathrm{g} / \mathrm{ml})$ with or without LPS (1 $\mu \mathrm{g} / \mathrm{ml}$ ) for $4 \mathrm{~h}$. The nitrite in the culture supernatant was evaluated using Griess reagent. Data are presented as the mean \pm S.E.M. $(n=3)$ for three independent experiments. ${ }^{\#} p<0.001$, when compared with control group. ${ }^{*} p<0.05,{ }^{* *} p<0.01$ and ${ }^{* *} p<$ 0.001 , when compared with LPS alone treated group by one-way analysis of variance, followed by Dunnett's multiple range tests. SM-EA extract = Suaeda maritima ethyl acetate extract; LPS: lipopolysaccharide

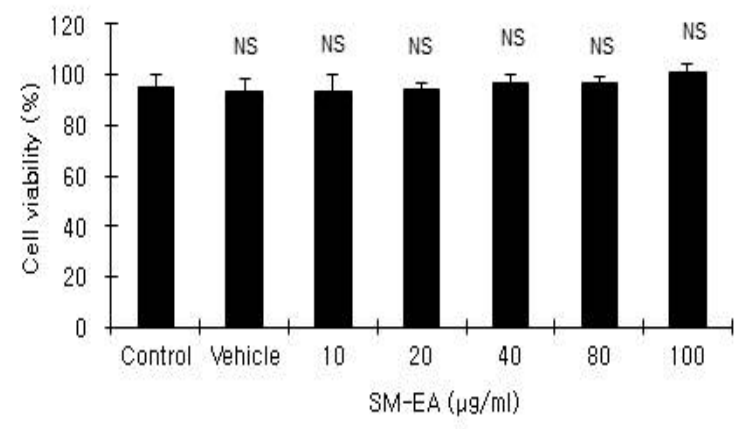

Fig 3: Effects of SM-EA extract on the viability of BV-2 microglial cells. Viability in SM-EA extract treated cells was determined using MTT assay. The results are displayed in percentage of control samples. Data are presented as the mean \pm S.E.M. $(n=3)$ for three independent experiments. NS Not significant. SM-EA extract $=$ Suaeda maritima ethyl acetate extract

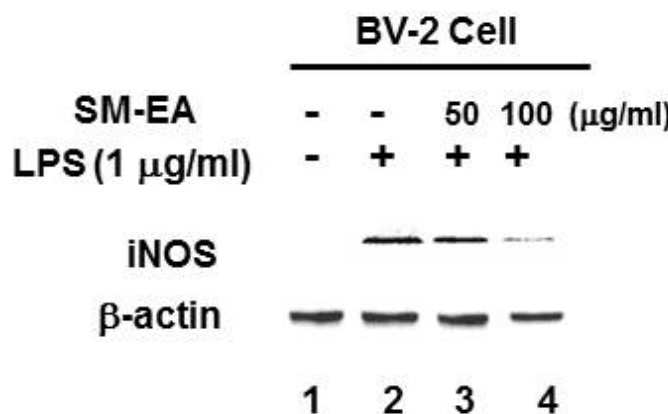

Fig 4: Effect of SM-EA extract on iNOS protein expressional levels in LPS-stimulated BV-2 microglial cells. The expression levels of iNOS production in the LPS-stimulated BV-2 cells by indicated concentrations (50 and $100 \mu \mathrm{g} / \mathrm{ml}$ ) of the SM-EA extract was monitored by immunoblot analyses with the specific antibodies against iNOS. The internal control used was $\beta$-actin. SM-EA extract = Suaeda maritima ethyl acetate extract; LPS= Lipopolysaccharide; iNOS: Inducible nitric oxide synthase

\section{Effect of SM-EA extract on IL-6 production in LPS-stimulated BV-2 cells}

BV-2 microglia was pretreated with SM-EA extract for $30 \mathrm{~min}(10,20,40$ and $80 \mu \mathrm{g} / \mathrm{ml})$ with or without LPS $(1 \mu \mathrm{g} / \mathrm{ml})$. As shown in Fig. 6, LPS stimulation increased the IL-6 expression in BV- cells. However, SM-EA extract pretreatment decreased the LPS-induced IL-6 levels in BV-2 microglia (Fig. 5).

\section{Effect of SM-EA extract on TNF- $\alpha$ production in LPS-stimulated BV-2 cells}

As shown in Fig. 6, TNF-a levels increased significantly after LPS treatment $(1 \mu \mathrm{g} / \mathrm{ml})$ when compared to those in untreated cells $(p<0.001)$. 
However, SM-EA extract significantly inhibited TNF- $\alpha$ production in a concentration-dependent manner in LPS-stimulated BV-2 cells $(p<0.05$ at $40 \mu \mathrm{g} / \mathrm{ml}$ and $p<0.001$ at $100 \mu \mathrm{g} / \mathrm{ml}$, respectively).

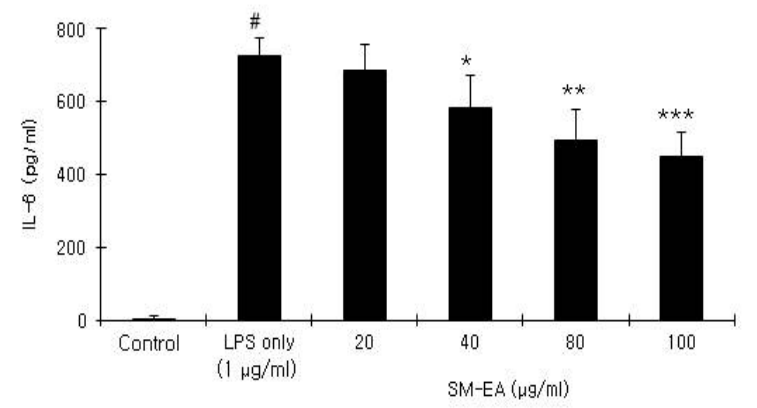

Fig 5: Effect of SM-EA extract on pro-inflammatory cytokine IL-6 expression in LPS-stimulated BV-2 cells. BV-2 cells were treated with SM-EA extract at indicated concentrations $(20$, $40,80$ and $100 \mu \mathrm{g} / \mathrm{ml})$ with or without LPS $(1 \mu \mathrm{g} / \mathrm{ml})$ for $4 \mathrm{~h}$. The IL-6 in the culture supernatant was evaluated using a murine IL-6 ELISA kit from BD Sciences according to the manufacturer's instruction. Data are presented as the mean \pm S.E.M. $(n=3)$ for three independent experiments. ${ }^{*} p<0.001$, when compared with control group. ${ }^{*} p<0.05,{ }^{* *} p<0.01$, ${ }^{* * *} p$ $<0.001$, compared with LPS alone treated group by one-way analysis of variance, followed by Dunnett's multiple range tests. SM-EA extract = Suaeda maritima ethyl acetate extract; LPS= lipopolysaccharide; IL-6= Interleukin-6

\section{DISCUSSION}

In the present study we report that SM-EA extract significantly inhibited production of NO, suppressed the expression of iNOS protein level and attenuated the increased levels of IL- 6 and TNF- $\alpha$ production in LPS-simulated BV-2 microglial cells. Further the SM-EA extract exhibited significant antioxidant activity evaluated by DPPH free radical scavenging method. Free radicals and reactive oxygen species (ROS) are important causative factors in the development of age-related neuroinflammatory and neurodegenerative diseases [11]. Thus neutralization by antioxidants and radical scavengers can reduce neuroinflammation. It was well known that DPPH radical assay as one of the widely used methods for evaluating the free radical scavenging activities of several antioxidants in a relatively short period of time [12]. Earlier studies revealed that $S$. maritima possessed strong antioxidant polyphenolic and sterol compounds [2,3]. In our present study, the ethyl acetate fraction obtained from the SM-EA extract also exhibited significant free radical scavenging effect indicating that the SM-EA might contain potential antioxidant agents. Since antioxidants might reduce neuroinflammation [11], we used SM-EA extract to evaluate for its antineuroinflammatory activity in LPS-stimulated BV2 microglial cells.

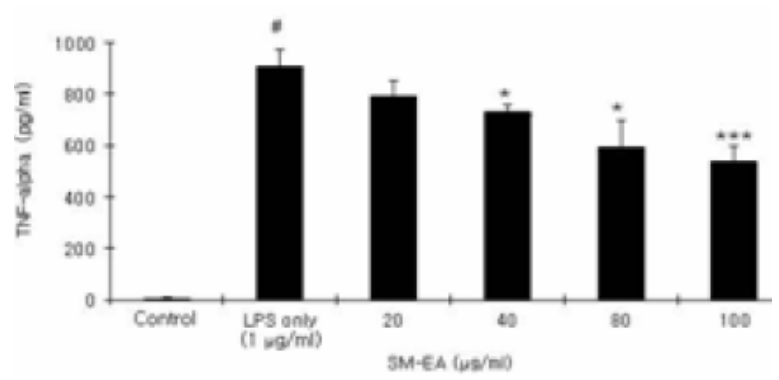

Fig 6: Effect of SM-EA extract on TNF-a production in LPSstimulated BV-2 microglial cells. Suppression of proinflammatory cytokine TNF- $\alpha$ expression by SM-EA extract was measured with ELISA test. BV-2 cells were treated with SM-EA extract at $20,40,80$ and $100 \mu \mathrm{g} / \mathrm{ml}$ with or without LPS $(1 \mu \mathrm{g} / \mathrm{ml})$ for $4 \mathrm{~h}$. The TNF- $\alpha$ in the culture supernatant was evaluated using a murine TNF- $\alpha$ ELISA kit. Data are presented as the mean \pm S.E.M. $(n=3)$ for three independent experiments. ${ }^{\#} p<0.001$, when compared with control group. ${ }^{*} p<0.05$, and ${ }^{* * *} p<0.001$, when compared with LPS alone group by Student t-test. (SM-EA- Suaeda maritima ethyl acetate extract; TNF-a: Tumor necrosis factoralpha; LPS: Lipopolysaccharide)

A significant number of reports have established that inflammatory mediators, including $\mathrm{NO}$ and iNOS are responsible for the symptoms of many neuroinflammatory diseases It is well documented that microglia produces NO in response to pro-inflammatory stimuli LPS. The induced NO by the induction of iNOS will lead to increased inflammatory reaction. Therefore, agents that decrease NO production and iNOS have appreciable therapeutic effect in the treatment of several neuroinflammatory diseases $[13,14]$. Our results clearly showed that SM-EA extract attenuated LPS-induced iNOS expression and downstream NO production.

Proinflammatory cytokines such as TNF- $\alpha$ and IL-6 cause potent activation of iNOS gene expression in rodent glial cells and muscle cells [15]. Microglial cell activation by LPS produces various cytokines including IL- 6 and TNF- $\alpha$ leading to the attraction of neutrophils and the accumulation of neutrophil-secreted proteases and ROS at the site of inflammation. Data from our study showed that SM-EA extract may act by suppressing the increased production of IL- 6 and TNF- $\alpha$ thereby inhibiting NO production and iNOS expression levels in LPS-stimulated BV-2 cells indicating that SM-EA extract may convincingly be an effective antineuroinflammatory agent.

\section{CONCLUSION}

SM-EA plays an important role in attenuating neuroinflammatory responses in LPS-stimulated BV-2 microglial cells. The anti-neuroinflammatory 
effects of SM-EA extract may be attributed to its regulatory actions on proinflammatory cytokine such as TNF- $\alpha$ and IL-6. The strong antioxidant effects exhibited by SM-EA extract may also be involved in delivering such actions. Thus, SM-EA extract may be developed as a promising candidate for the treatment of neuroinflammation-mediated neurodegenerative disorders.

\section{REFERENCES}

1. Tahnaka T. Tanaka's cyclopedia of edible plants of the world, (Keigaku Publishing Co, Tokyo) 1976.

2. Ravikumar S1, Gnanadesigan $M$, Inbaneson SJ, Kalaiarasi A. Hepatoprotective and antioxidant properties of Suaeda maritima (L.) dumort ethanolic extract on concanavalin-A induced hepatotoxicity in rats. Indian J Exp Biol. 2011; 49(6):455-60.

3. JK Patra1, NK Dhal2, HN Thatoi3*. In vitro bioactivity and phytochemical screening of Suaeda maritima (Dumort): A mangrove associate from Bhitarkanika, India. Asian Pacific J Trop Med 2011; 4: 727-734.

4. Perry VH, Gordon S. Macrophages and microglia in the nervous system. Trends Neurosci 1988; 11:273-277.

5. Liu B, Hong J.S. Role of microglia in inflammationmediated neurodegenerative diseases: mechanisms and strategies for therapeutic intervention. J Pharmacol Exp Ther 2003; 304: 1-7.

6. Xie Q.W., Kashiwabara $Y$, Nathan C. Role of transcription factor NF-kappa B/Rel in induction of nitric oxide synthase J Biol Chem 1994; 269(7): 4705-4708.

7. Agullo G, Gamet-Payrastre L, Manenti S, Viala C, Rémésy $\mathrm{C}$, Chap $\mathrm{H}$, et al. Relationship between flavonoid structure and inhibition of phosphatidylinositol 3-kinase: a comparison with tyrosine kinase and protein kinase $C$ inhibition. Biochem Pharmacol 1997; 53:2087-2094.

8. Araki E, Forster C, Dubinsky JM, Ross ME, ladecola C. Cyclooxygenase-2 inhibitor NS-398 protects neuronal cultures from lipopolysaccharide-induced neurotoxicity. Stroke 2001; 32:2370-2375.

9. Nanjo F, Goto K, Seto R, Suzuki M. Scavenging effects of tea catechins and their derivatives on 1,1-diphenyl2-picrylhydrazyl radical. Free Radic Biol Med 1996; 21: 895-902.

10. Kim BW, Koppula S, Kim IS, Lim HW. Antineuroinflammatory activity of Kamebakaurin from Isodon japonicus via inhibition of C-Jun NH-terminal kinase and p38 mitogen-activated protein kinase pathway in activated microglial cells. J Pharmacol Sci 2011; 116: 296-308.

11. Finkel $T$, Holbrook NJ. Oxidants, oxidative stress and the biology of ageing. Nature 2000; 408: 239-247.

12. Sanches-Moreno C, Plaza L, Ancos B, Cano MP. Nutritional characterization of commercial trnaditional pasteurized tomato juices: carotenoids, vitamin and radical-scavenging activity. Food Chem 2006; 98: 749-756.

13. Tuttolomondo A, Di Raimondo $D$, di Sciacca $R$, Pinto $A$, Licata G. Inflammatory cytokines in acute ischemic stroke. Curr Pharm Des. 2008; 14: 3574-3589.

14. Merrill JE, Benveniste EN. Cytokines in inflammatory brain lesions: helpful and harmful. Trends Neurosci. 1996; 19: 331-338.

15. Hunot S, Hartmann A, Hirsh EC. The inflammatory response in the Parkinson brain. Clin Neurosci Res 2001; 1: 434-443. 